\title{
Allium Ureteral Stent as a Treatment for Ureteral Stricture: Results and Concerns
}

\author{
Ofir Avitan $^{\mathrm{a}}$ Zaher Bahouth $^{\mathrm{a}}$ Sagi Shprits ${ }^{\mathrm{a}}$ Miguel Gorenberg ${ }^{\mathrm{b}}$ \\ Sarel Halachmi ${ }^{a}$ \\ aDepartment of Urology, Bnai-Zion Medical Center, Haifa, Israel; b Department of Nuclear Medicine, Bnai-Zion \\ Medical Center, Haifa, Israel
}

\section{Keywords}

Ureteral stricture · Allium stent · Ureteral stent

\begin{abstract}
Introduction: Ureteral strictures could be a chronic illness that leads to severe side effects and poor quality of life. A treatment with an Allium ureteral stent (URS), a self-expanding, large-caliber URS, was implemented in our department for ureteral stricture. Our study aim was to report the longterm results, including success rate, complications, and adverse effects. Methods: We retrospectively collected data on all patients who were treated with an Allium URS in our department between January 2017 and January 2021. Demographic, clinical, radiological, and perioperative parameters were retrieved and analyzed. The primary outcome was stricture resolution rates following stent removal. Results: Our cohort included 17 patients, 9 men and 8 women. The etiology of ureteral strictures was urolithiasis in $76.5 \%$ and pelvic procedure injury in $17.6 \%$. The overall success rate was $35.29 \%$ in an average follow-up of $10.42 \pm 2.39$ months after stent removal. A higher failure rate was observed in the urolithiasis etiology group ( $90 \%$ vs. $66.7 \%, p=0.38)$. The mean indwelling time of the Allium stent was $14.29 \pm 1.29$ months. Conclusions: Although an Allium URS could be considered
\end{abstract}

Karger@karger.com www.karger.com/uin

Karger!

BOPEN ACCESS
(C) 2022 The Author(s)

Published by S. Karger AG, Basel

This is an Open Access article licensed under the Creative Common Attribution-NonCommercial-4.0 International License (CC BY-NC) (http://www.karger.com/Services/OpenAccessLicense), applicable to the online version of the article only. Usage and distribution for commercial purposes requires written permission. as a feasible and attractive treatment of ureteral strictures, due to its minimal invasiveness, the success rate of this treatment is relatively low. Therefore, this option should be carefully considered and should be discouraged in young and fit patients and reserved for older unfit patients who are unwilling to undergo surgical repair of ureteral strictures.

(c) 2022 The Author(s)

Published by S. Karger AG, Basel

\section{Introduction}

Ureteral strictures can be treated by several approaches [1], including placement of ureteral stents (URSs) in patients unwilling or unfit for definitive treatment. The standard pigtail URS have many side effects, including tissue inflammatory reaction, infection, and tube encrustation, leading to frequent replacement [2].

In a previous study [3], we demonstrated the advantages of a self-expanding large-caliber nitinol URS (Allium $^{\circledR}$; Allium LTD, Caesarea, Israel), including reduced tissue ingrowth, large caliber, high anti-compression force, and safe use for up to 2 years without the need for exchange. The aim of this study was to report the longterm results of all patients who were treated with the Allium ${ }^{\circledR}$ URS at our department.
Correspondence to:

Ofir Avitan, ofir.avitan@gmail.com 
Table 1. Patients and ureteral stricture characteristics

\begin{tabular}{|c|c|c|c|c|}
\hline & $N$ & Mean \pm SEM & Range & $p$ value \\
\hline \multicolumn{5}{|l|}{ Age, years } \\
\hline Success & 6 & $62.5 \pm 2.83$ & 5373 & 0.29 \\
\hline Failure & 11 & $55.09 \pm 4.68$ & 3682 & \\
\hline \multirow[t]{2}{*}{ Total } & 17 & $57.71 \pm 3.24$ & 3682 & \\
\hline & Success & Failure & Total & $p$ value \\
\hline \multicolumn{5}{|l|}{ Gender, $n,(\%)$} \\
\hline Female & $3(37.5)$ & $5(62.5)$ & $8(47.1)$ & 0.86 \\
\hline Male & $3(33.3)$ & $6(66.7)$ & $9(52.9)$ & \\
\hline Total & $6(35.3)$ & $11(74.7)$ & 17 & \\
\hline \multicolumn{5}{|l|}{ Stricture cause } \\
\hline Unknown, $n$ & 0 & 1 & $1(5.9)$ & 0.38 \\
\hline Pelvic procedure, $n(\%)$ & $2(66.7)$ & $1(33.3)$ & $3(17.6)$ & \\
\hline Urolithiasis, $n(\%)$ & $4(30.8)$ & $9(69.2)$ & $13(76.5)$ & \\
\hline \multicolumn{5}{|l|}{ Stricture location, $n$, (\%) } \\
\hline Proximal & $3(33.3)$ & $6(66.7)$ & $9(52.9)$ & 0.97 \\
\hline Middle & $1(33.3)$ & $2(66.7)$ & $3(17.7)$ & \\
\hline Distal & $2(40.0)$ & $3(60.0)$ & $5(29.4)$ & \\
\hline \multicolumn{5}{|l|}{ Laterality, n, (\%) } \\
\hline Left & $6(50)$ & $6(50)$ & $12(70.6)$ & 0.049 \\
\hline Right & 0 & $5(100)$ & $5(29.4)$ & \\
\hline
\end{tabular}

\section{Methods}

Data from our institutional database regarding patients treated with an Allium URS, from January 2017 to January 2021, were retrospectively collected following institutional review board approval.

\section{Allium URS Stent}

The Allium URS was designed for the treatment of ureteral strictures. It is a self-expanding, large-caliber metal stent. It has a cover of a biocompatible, biostable polymer to make it a nonpermeable tube to prevent tissue ingrowth into the lumen and early encrustation. The Allium URS has a longitudinally flexibility and radial force to keep the ureter lumen open and has a unique unraveling feature to make its endoscopic removal.

\section{Surgical Technique}

Insertion of the Allium URS was performed under general anesthesia. An antegrade ureterogram was done in patients with indwelling nephrostomy, and a retrograde ureterogram in patients without a nephrostomy in order to visualize the stricture and position the stent properly. After the insertion of a guide wire, some strictures were dilated using balloon ureteral dilator inflated to $20 \mathrm{~atm}(1.72 \mathrm{MPa})$ according to the manufacturer's recommendations. The stent was then inserted (in a retrograde or antegrade fashion), and its position fluoroscopically confirmed.

Removal of URS was scheduled in 12-14 months following stent insertion. The removal was performed using a semirigid ureteroscope under general anesthesia, with an endoscopic grasper due to its unique unraveling feature.

Allium Ureteral Stent for Ureteral

Stricture: Results and Concerns
Follow-Up

Six weeks following Allium URS insertion, diethylenetriaminepentaacetic acid renogram was performed. If results of renography did not show obstruction, baseline ultrasonography was performed, and patients subsequently followed up with renal sonography, comparing changes in hydronephrosis.

Six weeks following the removal of Allium URS, a renal sonography and a diethylenetriaminepentaacetic acid renogram were performed. If the results showed no obstruction, patients were advised for sonographic follow-up and serum creatinine. Stent failure was defined as persistent hydronephrosis with a demonstrated obstruction in renography.

\section{Statistical Analysis}

Processing and analyzing the data were done using SPSS version 20 software (IBM, Armonk, NY, USA). To compare the categorical variables, we used the $\chi^{2}$ Pearson test. Comparison of independent variables was done by Student's $t$ test. The continuous variables were described by mean and standard error of the mean. The noncontinuous variables were described as percentages. A $p$ value below 0.05 was considered statistically significant.

\section{Results}

The study cohort included 17 patients, 8 women and 9 men, with a mean age of $57.71 \pm 3.24$ years. Table 1 represents the ureteral stricture properties and demographic data of all patients. 
Table 2. Allium stent peri-procedure variables

\begin{tabular}{|c|c|c|c|c|}
\hline & $N$ & Mean \pm SEM & Range & $p$ value \\
\hline \multicolumn{5}{|l|}{ Follow-up, months } \\
\hline Success & 6 & $9.93 \pm 4.13$ & 1.526 .43 & \multirow[t]{3}{*}{0.88} \\
\hline Failure & 11 & $10.69 \pm 3.07$ & 0.4331 .7 & \\
\hline Total & 17 & $10.42 \pm 2.39$ & 0.4331 .7 & \\
\hline \multicolumn{5}{|c|}{ Indwelling time of the Allium stent, months } \\
\hline Success & 6 & $14.03 \pm 2.57$ & 2.9720 .53 & \multirow[t]{3}{*}{0.87} \\
\hline Failure & 9 & $14.46 \pm 1.45$ & 7.7722 .13 & \\
\hline \multirow[t]{2}{*}{ Total } & 15 & $14.29 \pm 1.29$ & 2.9722 .13 & \\
\hline & Success & Failure & Total & $p$ value \\
\hline \multicolumn{5}{|c|}{ Previous ureteral stricture management, $n,(\%)$} \\
\hline Dilation & $3(27.3)$ & $8(72.7)$ & $11(64.7)$ & \multirow[t]{3}{*}{0.45} \\
\hline Endoureterotomy & $2(66.7)$ & $1(33.3)$ & $3(17.6)$ & \\
\hline No dilation & $1(33.3)$ & $2(66.7)$ & $3(17.6)$ & \\
\hline \multicolumn{5}{|c|}{ Ureteral dilation during Allium stent insertion, $n,(\%)$} \\
\hline Dilation & $4(28.5)$ & $10(71.5)$ & $14(82.3)$ & \multirow[t]{3}{*}{0.21} \\
\hline No dilation & $2(66.7)$ & $1(33.3)$ & $3(17.7)$ & \\
\hline Total & $6(35.3)$ & $11(74.7)$ & $17(100)$ & \\
\hline
\end{tabular}

The etiology of ureteral stricture was as follows: $13 \mathrm{pa}-$ tients $(76.5 \%)$ due to urolithiasis cause and $3(17.6 \%)$ due to pelvic procedure (two gynecological surgery and one aorto-bifemoral stent insertion). One patient had a stricture of unknown origin.

The vast majority of patients had a previous treatment for ureteral stricture. About 64.7 were treated with balloon dilatation, $17.6 \%$ with endoureterotomy, and only $17.6 \%$ were not previously treated.

The mean indwelling time of the Allium stent was $14.29 \pm 1.29$ months, with the shortest recorded time being 3 month (removed due to stent migration). This patient with early stent removal had a patent ureter during follow-up.

Patients were scheduled for stent removal in 12-14 months following stent insertion. However, 2 patients were left with their Alium stent because of failure to retrieve it.

Regarding complications, 5 patients presented with occluded stent, and all of them were grouped in the failure group. Three patients presented with obstruction of the stent due to urolithiasis and needed stone fragmentation before stent removal. In 2 cases, we were unable to remove the Allium URS safely, and a decision was made to leave the stent in, and both patients required long-term nephrostomy tube due to ureteral blockage. Two patients were diagnosed with a second distal ureteral stricture after the Allium stent removal.
Patients were divided into two groups according to the final result. Group 1 included 6 patients who needed no further treatment after the removal of the Allium URS during follow-up, and group 2 comprised of 11 patients who needed further intervention due to obstruction. The average follow-up was $10.42 \pm 2.39$ months without any difference between groups $(p=$ $0.88)$.

No significant differences were noted between the study groups in gender or age. Although the location of stricture did not impact the success rate, the laterality of the stricture showed a marginal statistical significance $(p=0.049$. Although all the successful treatments were on the left side, the failed cases were divided evenly between the right and left sides ( $54.5 \%$ vs. $45.5 \%$, respectively).

Several other parameters were analyzed for potential association with the success rate as shown in Table 2. It can be clearly noted that the previous treatments and balloon dilations did not impact the success rate. However, it is noteworthy that patients who suffered from ureteral stricture due to urolithiasis cause had higher failure rate compared to others, although this was not statistically significant ( $90 \%$ vs. $66.7 \%, p=0.38$ ). Moreover, indwelling time did not have a positive impact on success rate. 


\section{Discussion}

Ureteral stricture should be treated to prevent renal unit dysfunction. The management of ureteral strictures could be challenging. The primary treatment is usually done by insertion of a pigtail stent or nephrostomy tube followed by a definitive, usually surgical treatment. Another option for patients unwilling or unfit for surgical intervention is a constant indwelling URS or nephrostomy tube with periodic exchange. These options could carry a lot of inconvenience for patients.

An Allium URS could offer another treatment option, and we aimed to report our experience with it. The Allium URS has several advantages over other URSs. Its features include a wide-diameter, polymer cover that prevents tissue ingrowth, an ability to anchor in the ureter, and an increased radial force that allows the lumen to remain open even in cases of significant external pressure. The first reports of its efficacy were remarkable [3], and in this study, we reported its real-life efficacy in patients treated at our department.

The results of our study indicate that the stent can be easily inserted, regardless of the severity and location of the stricture, without significant complications. Stent migration was recorded in only one patient. Five stents were blocked during follow-up and necessitated early removal. Three stents were blocked due to ureteral stones, and 2 were blocked due to severe stricture at the distal end of the Allium stent.

Xiong et al. [4] reported the results of 83 patients who were diagnosed with a ureteral stricture after ureteroscopic lithotripsy and showed a $60.9 \%$ success rate when patients were treated with ureteral dilatation or endoureterotomy. A literature review made by Hafez et al. [5] reported success rates of endoureterotomy from $55 \%$ to $85 \%$ for benign ureteral strictures and balloon dilatation success rates from $48 \%$ to $88 \%$, with an overall mean of $55 \%$.

Although our results did not show statistically significant difference in the success rate between patients who were treated with ureteral dilatation or endoureterotomy before stent insertion and patients who did not undergo such treatments, there was a clear trend toward a better outcome of almost 20\%. Hence, ureteral dilatation or endoureterotomy should be considered prior to Allium URS insertion.

The success rate of surgical ureteral repair, regardless of the approach (open, laparoscopic, or robot-assisted), are $90 \%$ and above [4]. Seideman et al. [6] reported their results of 45 patients who underwent laparoscopic ureteral reimplantation due to distal ureteral stricture with an overall success rate of $96 \%$. They defined success as radiographic evidence of no residual obstruction, symptoms, renal deterioration, or need for subsequent procedures. Another study by Soares et al. [7]. reported the results of 10 patients who underwent laparoscopic ureteral reimplantation due to distal and middle ureteral stricture, with an overall success rate of $100 \%$. Kolontarev et al. [8] presented a systematic literature review of robotassisted laparoscopic (RAL) ureteral reconstruction involving 245 RAL and 76 open ureteral surgery cases and concluded that the recurrence stricture rates in RAL and open groups were similar of about $9 \%$.

When endoscopic treatment with balloon dilatation or endoureterotomy fails or not suitable, a definitive treatment by using the Allium URS becomes very attractive, due to its endoscopic approach and minimal invasiveness. In our study, we reported a success rate of $35 \%$ as a definitive ureteral stricture treatment, which is far lower than surgical repair. Hence, the decision should be carefully discussed with patients before opting for the Allium URS. On one hand, a trial with Allium URS could potentially treat ureteral stricture and avoid surgical procedure; on the other hand, failure of the Allium URS could cause a blocked ureter or a second stricture (18\%) that could increase the complexity of the following surgical procedures.

This study has several limitations that are mainly due to the small number of patients. However, the low longterm success rate of the Allium URS should encourage patients and urologists to avoid this option in younger patients and keep it as an option to be considered for specific unfit patients who could potentially benefit from it.

\section{Conclusions}

Although an Allium URS could be considered as a feasible and attractive treatment of ureteral strictures due to its minimal invasiveness, the success rate of this treatment is relatively low. In our opinion, it may be used in selected cases as a permanent stent but not as a tool of definitive treatment.

\section{Statement of Ethics}

The Ethics Committee of the Bnai-zion medical center approved this study (REC number: 0049-10-BNZ). The present study was carried out retrospectively, and the need to obtain written informed consent from the patients was waived by the Institutional Review Board. Personal identifiers of the patients were removed, and the data were analyzed anonymously. 


\section{Conflict of Interest Statement}

The authors have no conflicts of interest to declare.

\section{Funding Sources}

The authors received no financial support for the research, authorship, and/or publication of this article.

\section{Author Contributions}

O.A. and Z.B.: carried out the data collection and statistics analysis and wrote the paper; M.G.: participated in the design of the study; S.S.: collected the data; S.H.: conceived the study and participated in its design and coordination and helped to draft the manuscript. All authors read and approved the final manuscript.

\section{Data Availability Statement}

The data that support the findings of this study are not publicly available due to the containing information that could compromise the privacy of research participants but are available from the corresponding author O.A. upon reasonable request.

\section{References}

1 Meretyk S, Albala DM, Clayman RV, Denstedt JD, Kavoussi LR. Endoureterotomy for treatment of ureteral strictures. J Urol. 1992; 147(6):1502-6.

2 Al-Aown A, Kyriazis I, Kallidonis P, Kraniotis P, Rigopoulos C, Karnabatidis D, et al. Ureteral stents: new ideas, new designs. Ther Adv Urol. 2010;2(2):85-92.

3 Moskovitz B, Halachmi S, Nativ O. A new self-expanding, large-caliber ureteral stent: results of a multicenter experience. J Endourol. 2012;26(11):1523-7.
4 Xiong M, Zhu X, Chen D, Hossain MA, Xie Y, Gou X, et al. Post ureteroscopic stone surgery ureteral strictures management: a Retrospective Study. Int Urol Nephrol. 2020;52(5):8419.

5 Hafez KS, Wolf JS Jr. Update on minimally invasive management of ureteral strictures. J Endourol. 2003;17(7):453-64.
6 Seideman CA, Huckabay C, Smith KD, Permpongkosol S, Nadjafi-Semnani M, Lee BR, et al. Laparoscopic ureteral reimplantation: technique and outcomes. J Urol. 2009;181(4): 1742-6.

7 Soares RS, de Abreu RA Jr, Tavora JE. Laparoscopic ureteral reimplant for ureteral stricture. Int Braz J Urol. 2010;36(1):38-43.

8 Kolontarev K, Kasyan G, Pushkar D. Robotassisted laparoscopic ureteral reconstruction: a systematic review of literature. Cent European J Urol. 2018;71(2):221-7. 